\title{
European approaches to ensure good animal welfare
}

\author{
Isabelle Veissier ${ }^{\mathrm{a}, *}$, Andrew Butterworth ${ }^{\mathrm{b}}$, \\ Bettina Bock ${ }^{\mathrm{c}}$, Emma Roe $^{\mathrm{d}}$

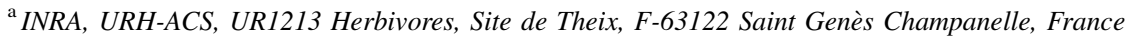 \\ ${ }^{\mathrm{b}}$ University of Bristol, Clinical Veterinary Science, Langford, North Somerset BS40 5DU, UK \\ ${ }^{\mathrm{c}}$ University of Wageningen, Rural Sociology Group, Hollandseweg 1, $6706 \mathrm{KN}$ Wageningen, The Netherlands \\ ${ }^{\mathrm{d}}$ University of Southampton, School of Geography, Highfield Campus, Southampton S017 1BJ, UK
}

Available online 7 March 2008

\begin{abstract}
Conventions to protect domestic animals during transport, farming and slaughter were established by the Council of Europe and approved by many European states. Conventions are followed by recommendations that specify how the general principles of conventions apply for the different species. The European Union (EU) started discussions on animal welfare in the 1980s and adopted a series of Directives to protect farm animals. Both Recommendations and Directives define higher space allowance, more opportunity for social contacts, balanced diet, enriched environment, and limitation of harmful procedures. Animal welfare law varies across Europe with Northern states generally having the most stringent legislation.

There is also an increasing variety of farm production schemes within European member states which contain animal welfare standards that go beyond the legal minimum. Some schemes are retailer-led; others are founded by producer organizations, sometimes in co-operation with non-governmental organisations. The differences between schemes reflect higher national legal requirements, higher quality industry schemes, organic production schemes and specific welfare-friendlier schemes. The communication of these higher welfare standards to consumers through the use of a quality assurance scheme logo on a product or packaging claims does not always happen. Farmers differ in their motivation for participating in animal welfare schemes. Some are mainly encouraged by premium prices; others give ethical reasons for changing towards animal friendly production methods.

Although there is no official link between the Brambell report and European regulations to protect farm animals, the fact that the first European regulations to protect animals were adopted 10 years after the report and were in line with the conclusions of the report suggest that the report was influential, not only in the United Kingdom but also in the rest of Europe.
\end{abstract}

(C) 2008 Elsevier B.V. All rights reserved.

Keywords: European legislation; Animal-welfare friendly products; Marketing schemes; Attitudes

* Corresponding author. Tel.: +33 473 624098; fax: +33 473624118.

E-mail address: veissier@clermont.inra.fr (I. Veissier). 


\section{Introduction}

Since the Brambell report (1965) was released, many initiatives have been adopted to increase farm animals' welfare. Although there is no official link between the Brambell report and European regulations to protect farm animals or initiatives by the private sector, the Brambell report was influential not only in the United Kingdom but also in the rest of Europe. The report increased awareness of politicians and societal groups about the (poor) conditions in which farm animals may live and about animals' capacity to suffer physically and mentally. In this article, we will review the legal protection of farm animals (both in terms of organisation and content) and the initiatives by the private sector (i.e. production schemes including welfare aspects and the market for welfare-friendlier foodstuffs). We will then compare the content of the Brambell report with these initiatives in order to highlight common features or dissimilarities.

\section{Regulations to protect farm animals in Europe}

In Europe, animal protection laws are issued and formulated by national governments. However, specific initiatives are produced by supra-national institutions, such as the Council of Europe and the European Union (EU), which stipulate minimum requirements that need to be adopted by all member states. The following section describes the different legislative texts currently used in Europe, outlines their content, and explains what motivated these regulations and to what extent science was involved in the construction of the texts.

\subsection{Conventions and recommendations from Council of Europe}

The Council of Europe, founded just after the Second World War (1949), was the first supranational organisation that proposed measures to ensure animal welfare. At present the Council of Europe comprises 46 member states (not all of which are in the EU). Its main components are: the committee of the foreign ministers of the 46 member states, which is a decision-making body, and the Parliamentary Assembly composed of 315 representatives of national parliaments. The inter-governmental activity programme drafts legal instruments, including conventions (binding on member and non-member states which ratify them) and recommendations (non-binding guidelines) with the aim of defending human rights and standardising member states' social and legal practices. It started to work on animal protection in the 1960s, with a belief that respect for animals was a common heritage of European countries closely linked to human dignity, and that harmonisation between countries was necessary. Five European Conventions lay down which ethical principles should guide the use of animals by people. Three European Conventions concern farm animals and two concern experimental animals and pets.

A committee of experts on the Protection of Animals drafted a convention to protect animals during transport by road, air, sea and rail. This resulted in the convention for the Protection of Animals during International Transport adopted by the committee of ministers of the Council of Europe in 1968. This convention lays down minimum requirements for the loading and unloading of animals and their transport per se (health of the animals, veterinary controls, handling, etc.). The committee of ministers subsequently created recommendations for the transport of horses (1987), pigs (1988), cattle (1990), sheep and goats (1990), and poultry (1990). Whereas European Conventions comprise fixed texts, which give general principles, recommendations are based on the scientific and technical knowledge available and can be revised when more knowledge becomes available. 
The convention for the Protection of Animals kept for Farming Purposes (1976) was prepared by the same committee of experts, on the basis of a text proposed by the World Federation for the Protection of Animals. It provided general principles for the keeping of animals in modern intensive systems defined as "systems which predominantly employ technical installations operated principally by means of automatic processes". Freedom of movement, housing and feeding that ensure good health, and daily inspection of both animals and equipment are set as basic requirements. A Standing Committee, which comprises representatives of each of the countries that signed the convention and observers from other countries or non-governmental organisations (veterinarians, farmers, animal protection associations, animal behaviour specialists, zootechnicians), created recommendations for each species according to the scientific and technical knowledge available. This committee had the mandate to create new recommendations or to revise existing ones. It made its decisions by a majority of votes of country representatives. Although observers cannot vote, they participate in debates and can launch ideas. Up to now, recommendations have been produced for cattle (1988, with a provision for calves in 1993), sheep and goats (1992), poultry (1986, 1995), ratites (1997), ducks, geese, and fur animals (1999), turkeys (2001), pigs (1986, 2005), and fish (2006). A recommendation for rabbits is under preparation and the recommendation for cattle is being revised.

Each recommendation starts from the biological characteristics of the species. It then lays down minimal requirements to ensure that the needs of the animals are fulfilled in regard to nutrition, health, freedom of movement, physical comfort, social contacts, normal behaviour, and protection against physical and psychological stressors. Special attention is given to appropriate training of stockpeople and to changes in genotype or physical appearance (e.g. to limit the use of mutilations).

The same committee of experts on the Protection of Animals drafted a convention for the Protection of Animals for Slaughter (1979). This convention aimed to improve the handling, lairage, restraint, stunning and slaughter conditions of domestic equids, ruminants, pigs, rabbits and poultry. Unnecessary suffering (e.g. rough handling of animals, striking sensitive parts of the body, extensive times in lairage, etc.) is to be avoided. Large animals shall be appropriately stunned, by means of a captive bolt or other mechanical stunning device, electro-narcosis or gas before bleeding-out so that they remain unconscious until death. Exceptions were provided for ritual or emergency slaughter. An expanded recommendation was produced in 1991 containing more detailed provisions.

The three conventions that protect farm animals were approved by 24 European countries (Belgium, Bosnia and Herzegovina, Bulgaria, Croatia, Cyprus, Czech Republic, Denmark, Finland, France, Germany, Greece, Ireland, Italy, Lithuania, Luxembourg, Netherlands, Norway, Portugal, Serbia and Montenegro, Slovenia, Spain, Sweden, Switzerland and the United Kingdom) and the EU. Five more countries (Austria, Hungary, Iceland, Malta and Spain) approved the convention to protect animals during farming. All of these countries are called "contracting parties".

When a convention or a recommendation is adopted, each contracting party undertakes to carry out measures to follow the recommendations (unless the contracting party objects to the text within a specific time). Depending on the countries, European Conventions are directly applicable, or need to be included in national law. For instance, the convention for the Protection of Animals kept for Farming Purposes was translated into an EU directive (Directive 98/58/EC). Recommendations can be implemented at a national level through legislative or administrative practice. Information on the Council of Europe in relation to animal welfare can be found at http://www.coe.int/. 


\subsection{Directives from the European Union}

The EU, initially called the European Economic Community (EEC), took initiatives to protect animals from the 1970s. The main motive was that disparities between national laws to protect animals could compromise fair competition within the common market (see introduction of Directive 78/923/EEC). The Amsterdam treaty (Anonymous, 1997) now recognised that animals are sentient beings and should be protected for this reason.

The EU Commission has the initiative to create legislative texts. Animal protection is under the responsibility of the General Directorate for the Health and Consumer Protection (DGSANCO). When a decision is taken about setting up a new piece of legislation to protect animals, DG-SANCO consults a scientific committee (formerly the Scientific Veterinary Committee, then the scientific committee on Animal Health and Animal Welfare, and now part of the European Food Safety Authority (EFSA)). In turn, the scientific committee appoints an ad hoc working group consisting of scientific experts recognised for their experience in the specific topic covered (e.g. welfare of pigs, of calves, etc.). This working group produces a report on existing systems and procedures for farming (or transport or slaughter), reviews the scientific evidence on the effects of any aspect that may affect animal welfare and provides recommendations on how to protect animals. Scientific reports were produced on the welfare of farm animals during transport (1992, 1999, 2002), slaughter (1996, 1998 for the stunning of poultry), rearing (calves: 1995, 2006; laying hens, 1996; pigs, 1997; ducks and geese, 1998); use of somatotropin in dairy cows (1999); broilers (2000); fattening cattle (2001); and fur animals (2001). According to the content of a report, DG-SANCO may decide to draft a directive. The Economic and Social Committee, made up of representatives of major societal stakeholders, can be consulted to give its opinion on a draft directive. A draft directive is submitted to the Council of Ministers of the EU and becomes a Council Directive only after receiving their approval. Some directives mention that after a certain time a new scientific report will have to be produced, and this can result in a possible revision of that directive. To date, European directives have been produced which concern all farm animal species during slaughter (Directive 74/577/EC replaced by Directive 93/119/EEC), transport (several directives, decisions and regulations from 1977) or rearing (Directives 78/923/ EC and 88/58/EC) as well as specific animals such as laying hens (Directive 88/166/EC replaced by Directive 1999/74/EC), calves (Directive 91/629 amended by Directive 97/2/EC), pigs (Directive 91/630/EEC amended by Directive 2001/93/EC). A directive for broilers has been proposed by the commission in 2005 and is now under discussion.

In general, the five freedoms (Farm Animal Welfare Council, 1992) guide the work of the EU. The general trends of EU Directives for the rearing of farm animals are:

- To increase space allowance per animal.

- To permit interactions between animals, and hence to encourage group housing (e.g. no calf shall be in an individual crate after 8 weeks of age).

- To give more freedom of movement (tethering is limited, muzzling is prohibited).

- To provide animals with an enriched environment (e.g. furnished cages for laying hens, substrate for rooting to pigs).

- To feed animals a regimen consistent with their physiological and behavioural needs (e.g. sows and gilts shall receive foods that are bulky in addition to being high in energy, veal calves shall not be anaemic).

- To limit painful intervention (e.g. tail docking and reduction of eye teeth in piglets is allowed only in cases of overt injury to sows or other pigs and after trying to reduce behavioural vices by 
other measures; beak trimming of poultry is allowed to prevent feather pecking and cannibalism only if it is performed by a qualified person and only on pullets less that 10 days of age).

EU directives are translated into national regulations (e.g. decrees) before they can be applied to farms in each country. The new European rural Policy (2007-2013) (European Commission, 2004) announced that direct payments to farmers within the EU will depend on farmers' following 'Good farming practises' that incorporate animal welfare legislation (crosscompliance). In addition, farmers may be paid for delivering extra public services in the field of environmental protection and animal welfare. To achieve this, farms will need to demonstrate levels of animal welfare through farming practice which move beyond the basal level that is defined by law.

Information on the activities of the EU to protect animals can be found at: http:// europa.eu.int.

\subsection{National regulations}

In parallel with the European legislation, all member states have their own national legislation. This legislation must at least conform to European regulations but may also define more stringent measures. For example, Sweden and Norway have stricter requirements for floor surface for weaned pigs, prohibit tail docking and teeth clipping, and limit weaning to piglets of at least 4 weeks. Norway demands that castration is done by a veterinarian using an anaesthetic, while in the other countries castration without anaesthesia is allowed for piglets less than 7 days of age, and is usually performed by the pig farmer. In the United Kingdom, Sweden and Norway, group housing for non-suckling sows is already required in all buildings (Bock and Van Huik, 2007).

Despite the various additional requirements defined in national regulation, it is remarkable how similar the welfare requirements for pig production are in most of the European countries. In general, Sweden, Norway and the UK tend to take the lead, having stricter regulations for all farm animals covered by EU regulations (Bock and van Leeuwen, 2005) whereas in other countries like France, Italy or Hungary, the regulations are at the level of European standards.

To really understand how animal welfare is regulated in each EU country, we must look beyond the law. In the UK, for instance, the government has published Codes of Practice to ensure 'best practice' in the management and handling of animals. They are used to clarify legal requirements and suggest best practice procedures for their implementation. Codes of Practice generally aim at a higher level of animal welfare than is stipulated legally, and should be understood as a significant mechanism for a general increase in animal welfare standards across farms. Some retailers publish Codes of Practice that express guidelines about animal welfare. They can be more general or more detailed than government Codes of Practise, thus reflecting varying commitments to sourcing welfare-friendlier foodstuff. An example of what is included in Codes of Practice, and is thus considered as 'best practice' in the UK industry is the use of 'veterinary health plans'. Health planning includes the recording of any health problem on the farm, then the identification of main health problems and the creation of a strategy to improve the situation. In some countries animal welfare measures are integrated in farm and retailer (quality assurance) schemes (see below). Often what forms part of Codes of Practice becomes mandatory under such schemes. 


\section{Initiatives by the private sector: production schemes}

\subsection{Quality assurance schemes}

Quality assurance is described by Early (1995) as "a strategic management function concerned with the establishment of policies, standards and systems for the maintenance of quality". For agriculture, the growth in food safety legislation across European nations and the EU Directive on the Hygiene of Foodstuffs (1993), has been influential in the development of industry-based farm assurance schemes, and the increasing use of these by retailers as a quality 'gate-keeping' device. Both farm and retailer assurance schemes may include animal welfare, often to attract a specific group of consumers (Manning et al., 2006). Such schemes may add to and 'upgrade' legislation. This is the case in the pig-sector in the UK where farmers have little choice but to enter farm assurance schemes that entail stricter regulations, for instance, in banning castration.

In Europe, some schemes operate where there is explicit use of marketing of better animal welfare. These schemes have been initiated by governments, non-governmental organisations and industry and by initiatives from manufacturers, producers, or a consortium. The motivation of governments at regional or state level to initiate the use of a logo or label to market quality products is predominantly aimed at protecting a geographically specific market, for example the Agriqualita label in Italy. Ethical concerns are generally the driver for schemes that originate from non-governmental organisations (e.g. "Nature et Progrès" in France "Scharrel" in The Netherlands and the Soil Association in the UK). Typically, the ethical motivations of nongovernmental organisations are broader than animal welfare and aim towards promoting sustainable production schemes. An exception is the Freedom Food scheme in the UK (founded in 1994 by the Royal Society for the Prevention of Cruelty to Animals (RSPCA)) which focuses primarily on animal welfare. Industry initiatives to set up production schemes that deliver higher quality products are found all across Europe (e.g. Miljöhusesyn in Sweden, commodity sector assurance schemes launched in the UK and Label Rouge in France). Animal welfare is not the specific focus of these production schemes but may be a component of the scheme aimed at guaranteeing a certain quality level of production throughout the supply chain.

The development of a growing market for welfare-friendly foodstuffs across Europe is likely to be a key mechanism for further developments in animal welfare standards, one that appears not to have been foreseen by Brambell when writing in 1965. The tensions between Europe's global lead on animal welfare, the realities of World Trade Organisation (WTO) agreements and the wider global market, have led to alternative market-led initiatives to meet European's consumer concerns about the treatment of farm animals. But participation in such schemes also reflects differences among farmers in their attitudes and beliefs concerning animal welfare and is an important motivation for engaging in more animal friendly production methods.

\subsection{Links between quality assurance schemes and animal welfare}

There are basically three types of production schemes that demonstrate increasing levels of welfare regulation: basic and top level general quality assurance schemes, specific animal welfare schemes and organic schemes (Bock and van Leeuwen, 2005).

\subsubsection{General quality (farm) assurance schemes: basic and top level}

General quality assurance schemes (such as KSL in Norway, MHS in Sweden, IKB in The Netherlands, BFS in UK, CCP in France and QC in Italy) contain an animal welfare module but 
focus on other aspects, such as food safety, product quality and traceability. In basic quality assurance schemes, animal welfare criteria follow only the basic legal requirements, whereas they surpass legal requirements at least to some extent in top quality assurance schemes. In some sectors, participation in a general quality scheme may be optional in theory but obligatory in practice, in order to achieve market access. In the UK for instance $90 \%$ of pig farmers participate in the Assured British Pigs scheme, whose animal welfare requirements considerably exceed legal regulations.

\subsubsection{Specific animal welfare schemes}

A number of specific animal welfare schemes aim to improve animal welfare. They considerably surpass national legislation and are generally also above the standards agreed upon in top quality schemes. They are often the initiative of non-governmental animal protection organisations seeking co-operation with industry. Such has been the case with 'Scharrel' in The Netherlands (founded by the initiative of the association for the Protection of Animals, the Ministry of Agriculture and the Consumer Association) and Freedom Food in the UK (founded in 1994 by the RSPCA), or Thierry Schweitzer Pork (France, founded in 1999 by one farmer). Specific animal welfare schemes can also be set up by industry alone in order to enter a specific market, such as in the case with 'Good Farming Welfare' in the Netherlands, designed by one of the leading animal feed industries to enter the UK pig market in 2003. Most of these schemes demand more space for the animals, the use of natural lighting, group housing or free-range housing, the availability of play-material or material that encourages and enables natural behaviour (like litter) and outdoor access. Some of them have requirements regarding the type of food (e.g. only plant derived feed for poultry) or the treatment of young animals (e.g. weaning age). Others constrain surgery on the animal, e.g. castration without anaesthesia and docking of tails, etc. For more detailed information about the regulations in various specific animal welfare schemes see Bock and van Leeuwen (2005).

\subsubsection{Organic production schemes}

In organic schemes, animal welfare is included as part of the basic production philosophy, alongside environmental and human health, food safety and food quality. In most countries the animal welfare requirements in organic regulations surpass animal welfare legislation (see for instance KRAV in Sweden, Debio in Norway, Soil Association in UK, Agriculture Biologique in France, SKAL in the Netherlands and AIAB in Italy). This is, however, not the case in the UK where Freedom Food defines the most stringent animal welfare requirements. Generally it may be said that these regulations refer to natural behaviour in terms of feed, room for movement and social behaviour and physical integrity. Space requirements are generally higher, outdoor access is mandatory and surgery such as castration, dehorning and beak trimming are generally forbidden.

\subsection{Farmers motivations to join a welfare scheme}

Farmers' participation in schemes is related to the farmers' own definition of animal welfare and readiness to implement animal welfare measures. On the basis of research among pig farmers, two groups of farmers may be distinguished (Bock and Van Huik, 2007). The first group defines animal welfare primarily in terms of animal health. These farmers consider animal welfare important as it impacts on animal performance and, thus, economic results. The second group defines welfare mainly by the ability of the animals to express natural behaviour. The farmers underline their moral obligation when explaining why animal welfare matters to them; 
production and economic performance is mentioned as a secondary motive. The first, more production-oriented concept of animal welfare is used more often (but not exclusively) by farmers in the general quality assurance schemes and by those farmers who do not participate in any scheme. The second concept of animal welfare, focusing on natural behaviour, is more often used (but not exclusively) by farmers in special animal welfare and organic schemes. These groups of farmers also differ regarding their attitude to animal welfare regulations. On average, farmers who are already engaged in animal friendly production methods as a result of their participation in specific animal welfare schemes or organic farming think positively about regulation, and are in favour of a further tightening of legislation. This may be explained by the fact that they are already ahead of national legislation. Further tightening of regulations will thus hardly affect their daily practice. But it is also quite clear that they believe in animal welfare as a societal demand that farmers cannot avoid if they wish to keep their 'licence to produce'. In addition, some of these farmers successfully entered a market where they could sell their animal friendly products at a premium price. However, many farmers are disillusioned by the marketability of animal friendly products. They are disappointed by the low level of consumers' interest and by retailers' efforts to promote these products, and retailers' continual importation of cheaper meat products produced under less animal friendly circumstances.

Beneath the different attitudes of the two groups of farmers towards animal welfare issues, lies a more fundamental difference in farming style or production logic (Bock and Van Huik, 2007). The majority of the first group of farmers produce meat for the conventional market where the price is low and profit depends on the quantity of meat produced at a low cost. In this context a good farmer is an efficient farmer, producing lots of meat for minimal cost. When the objective of agriculture is more broadly defined, and includes for instance care for nature and environment, such as in the organic scheme, the definition of good farming and good animal welfare will concomitantly change as well. In this context it makes much more sense to take natural behaviour into account and to consider 'naturalness' as a valuable result. Specific animal welfare schemes and organic farming provide a context where such behaviour is stimulated and rewarded by a premium price that compensates the higher costs involved. In contrast, general quality assurance schemes are part of the conventional production logic and provide no incentives for a change in attitude or behaviour.

\subsection{The market for welfare-friendly foodstuffs}

Currently, many national governments across Europe prefer to implement any further improvements in animal welfare by way of the market rather than by increasing national legal standards. But it is important to understand that the market does not necessarily communicate to consumers through product packaging or promotional material when a product has been produced to higher animal welfare standards. In other words when something is produced which complies to a farm assurance scheme, the product packaging may carry a quality assurance scheme logo but perhaps no accompanying text that draws attention to its welfare-friendlier status. And, in other circumstances it may not even carry the quality assurance scheme logo.

\subsubsection{Retailer-brand positioning}

Retailer-brand lines are a popular development in major retail stores. They are seen as a way to encourage brand-loyalty to a retailer through the communication of a retailer's values through the brand. The brand is a package of different values that the retailer sees as attractive to their customers. European retailers hold a range of positions towards animal welfare and the increasingly differentiated retail market by product quality is illustrated in Table 1 . The position the 
retailer has in the market and the particular sector of the market that they are aiming for affect the particular bundle of values that are promoted by the company brand. They may try to appeal to a broad-range of consumers, or specifically to an affluent social group, or to a price-driven lessaffluent social group, or to special occasion consumers. Whichever they are, their communication strategy about animal welfare-friendliness will differ accordingly. Thus, retailers may decide to market the same product, produced under the same assurance scheme, in different ways and as either a conventional product attuned to the price-driven consumers, or as an animal friendly product meant for the special occasion consumer; this is known as 'value-engineering'. The communication of welfare-friendliness is increasingly used as part of a 'value-engineering' strategy. The logo used by the retailer in order to market the product does not always match with the conditions under which an animal has been raised, and so the issue of "credibility" is raised. And whereas production regulations are regularly checked by certification institutions, promises made on product packaging are generally not externally checked. It is also worth noting that the admirable Company Board ambition about animal welfare is not always possible in practice on the shop-floor.

\subsubsection{Welfare-friendly slogans and welfare-friendly descriptions}

There are some welfare-friendly product descriptions that have become recognisable slogans and product differentiators. These slogans have gained a more stable identity in product marketing and are widely used in the industry. Most recognisable and widely known is the "freerange' slogan, used on both eggs and poultry products. A slogan that is starting to emerge in the UK, Dutch and Norwegian pork industry is the term 'outdoor reared'. There is noticeably less development of a welfare-friendly slogan across dairy and beef product ranges; emphasis is on the quality of the dairy product or meat rather than the quality of the animal's life. This situation may ultimately lead to less development in welfare standards for cattle if the market is the major driver for increasing standards.

Packaging description which suggests welfare-friendliness is often found on organically produced products across all product ranges. Across all products there is a huge variation in the detail of description on packaging about the production system (Roe et al., 2005). Some have just a single statement for example "If animal welfare is important" by the Norwegian producer cooperative Nordgarden. Other labels make statements related to how the animal has lived, for example 'From free-range indoor hens'. Others bundle animal welfare or animal well-being in with a number of other attractive product attributes including animal health, ecological and sociological issues, human health and quality/taste (Roe et al., 2005).

A number of factors affect the communication of a product as welfare-friendly and the marketing strategy chosen. These include:

- the brand values of the retailer in which the products are found;

- product packaging description that is configured by the active differentiation of quality within a category;

- the use of a welfare-friendly slogan.

Thus, there is a complexity to the visibility of welfare-friendly foodstuffs in the market reflecting various retailing and marketing techniques.

\subsubsection{European welfare-friendly market}

There are marked differences in the availability of labelled welfare-friendly foodstuffs that are often the opposite to what one might expect (Table 2). In Norway and Sweden where there 
Table 1

Four categories of welfare marketing characteristics, specific to products in-store that carry animal welfare claims on packaging, for different retailers in different countries (from Roe and Marsden, 2007)

\begin{tabular}{|c|c|c|c|c|}
\hline \multirow[t]{2}{*}{ Country } & \multicolumn{4}{|l|}{ Type of claims } \\
\hline & $\begin{array}{l}\text { Welfare focused strategies } \\
\text { in marketing of quality }\end{array}$ & $\begin{array}{l}\text { Organic, less explicit } \\
\text { welfare }\end{array}$ & Quality and welfare & $\begin{array}{l}\text { Rare to find welfare } \\
\text { or none }\end{array}$ \\
\hline UK & $\begin{array}{l}\text { Marks \& Spencers, Waitrose, } \\
\text { Sainsbury, Fresh 'n' Wild }\end{array}$ & $\begin{array}{l}\text { Organic supermarket, } \\
\text { independents }\end{array}$ & $\begin{array}{l}\text { Tesco, Somerfield, } \\
\text { Morrisons }\end{array}$ & $\begin{array}{l}\text { Coop, Asda, Farmer's } \\
\text { market, Lidl }\end{array}$ \\
\hline Italy & Esselunga, Coop, Conad & Natura $\mathrm{Si}$ & $\begin{array}{l}\text { Despar, Proda, Sigma, } \\
\text { Standa, GS-Carrefour }\end{array}$ & Lidl \\
\hline France & & Rayon Vert & $\begin{array}{l}\text { Carrefour, Auchan, Casino, } \\
\text { System U, Monopix, } \\
\text { Leclerc, intermarche }\end{array}$ & Lidl, Ed \\
\hline Sweden & $\begin{array}{l}\text { Hemkop, ICA Malmsborgs, } \\
\text { ICA, Coop Forum/Hypermarket, } \\
\text { Coop Konsum/convenience store }\end{array}$ & & $\begin{array}{l}\text { Citygross/Hypermarket, } \\
\text { Maxi ICA/Hypermarket, } \\
\text { AGS/Supermarket }\end{array}$ & Willys \\
\hline The Netherlands & $\begin{array}{l}\text { Albert Heijn, Konmar, } \\
\text { PLUS, Super de Boer }\end{array}$ & $\begin{array}{l}\text { Natuurwinkel (The } \\
\text { Nature Shop) }\end{array}$ & C1000, Edah & Aldi, Lidl \\
\hline Norway & & Helios & $\begin{array}{l}\text { Ultra, Centra, Meny, ICA Maxi, } \\
\text { ICA supermarket, Coop Obs, } \\
\text { Coop Prix, Coop Mega, } \\
\text { Meny Champion, Smart Club }\end{array}$ & $\begin{array}{l}\text { Rimi, REMA1000, } \\
\text { Kiwi, Joker }\end{array}$ \\
\hline
\end{tabular}


Table 2

An illustration of the number of welfare-friendly products across six European countries and also the sector of the industry that is behind the brand that conveyed animal welfare-friendliness (from Roe and Marsden, 2007)

\begin{tabular}{|c|c|c|c|c|c|c|c|}
\hline \multirow[t]{3}{*}{ Country } & \multicolumn{7}{|c|}{ Origin of animal welfare brand } \\
\hline & \multicolumn{2}{|c|}{ Producer brand } & \multicolumn{2}{|c|}{ Retailer-brand } & \multicolumn{2}{|c|}{ Manufacturer brand } & \multirow{2}{*}{$\begin{array}{l}\text { Total } \\
\text { No. of } \\
\text { products }\end{array}$} \\
\hline & $\begin{array}{l}\text { No. of } \\
\text { products }\end{array}$ & $\begin{array}{l}\% \text { of } \\
\text { products }\end{array}$ & $\begin{array}{l}\text { No. of } \\
\text { products }\end{array}$ & $\begin{array}{l}\% \text { of } \\
\text { products }\end{array}$ & $\begin{array}{l}\text { No. of } \\
\text { products }\end{array}$ & $\begin{array}{l}\% \text { of } \\
\text { products }\end{array}$ & \\
\hline France & 43 & 22 & 62 & 31 & 93 & 47 & 198 \\
\hline UK & 12 & 10 & 53 & 44 & 56 & 46 & 121 \\
\hline Norway & 7 & 6 & 2 & 2 & 106 & 92 & 115 \\
\hline Sweden & 42 & 58 & 9 & 12 & 17 & 24 & 68 \\
\hline Italy & 0 & 0 & 33 & 40 & 50 & 60 & 83 \\
\hline The Netherlands & 85 & 30 & 57 & 21 & 138 & 49 & 280 \\
\hline
\end{tabular}

This study provides only an illustration of the diversity of products that carry welfare-claims. Therefore, unlabelled welfare-friendly initiatives are not included (e.g. Coop Italia that sells pork products which are produced at a nonintensive farming level, but this is not labelled on the product but instead is advertised through in-store advertising, is not included).

is higher national animal welfare legislation there are less products available that carry welfare-friendly labelling (Roe et al., 2005). In these countries ensuring good animal welfare is considered the responsibility of governments through legislation by both consumers and farmers (Bock and Van Huik, 2007). Therefore the market has not responded by differentiating products based on improved animal welfare in part because higher legislation has made it a non-issue. However, as the discount retail chains are beginning to gain market position in northern European countries, it is becoming more important to market nationally produced products in those open-economy countries like Sweden, because they are likely to meet higher-welfare standards than the cheaper foreign imports. The Swedish Meats label is an example of a communication strategy to consumers which allows them to differentiate between Swedish and non-Swedish products. Whereas in the closed-economy of Norway, where imports carry heavy tariffs, this is currently less of a concern (Murdoch, 2005). In Italy, France and Hungary, animal welfare is much less a public concern, and thus it is harder for the market to make it a competitive issue on the shelf. The UK is an interesting case where we find high national regulations resulting from a pronounced public concern with animal welfare but also production and retailers schemes with even tighter rules. As membership of these schemes practically regulates market access, UK farmers are forced to follow very high animal welfare standards. However, they see themselves at the same time confronted with huge quantities of imported pork meat produced under less stringent animal welfare regulations and which is cheaper (Bock and Van Huik, 2007). In countries where higher national legislation for animal welfare does not exist, and where there is no significant level of public interest in animal welfare, there is a barrier to the extent to which animal welfare standards can increase. But where strong national legislation goes together with high public concern and a governance tradition of commoditizing public issues, the resulting dominant position of retailers and processors may also significantly increase competition among farmers. In addition, the use of a logo as part of a marketing strategy has the potential to damage the credibility of animal welfare schemes in the long run if they are seen as marketing gimmicks alone which may then evoke distrust among consumers. 
The most important minimum animal welfare requirements for pig farming (from Bock and Van Huik, 2007)

\begin{tabular}{|c|c|c|c|c|c|c|c|c|}
\hline & European Union (EU) & Norway & Sweden & France & \multicolumn{2}{|l|}{ Netherlands } & United Kingdom & Italy \\
\hline \multicolumn{9}{|c|}{ Minimum surface requirements in $\mathrm{m}^{2}$ per animal ${ }^{\mathrm{a}}$} \\
\hline \multicolumn{5}{|c|}{ Weaned and fattening pigs } & \multicolumn{4}{|c|}{ Old stables New stables } \\
\hline$<10 \mathrm{~kg}$ & 0.15 & 0.15 & $0.25-0.32$ & \multirow[t]{7}{*}{$\mathrm{EU}$} & 0.20 & 0.20 & \multirow[t]{7}{*}{ EU } & \multirow[t]{7}{*}{ EU } \\
\hline $10-20 \mathrm{~kg}$ & 0.20 & 0.20 & $0.32-0.40$ & & 0.20 & 0.40 & & \\
\hline $20-30 \mathrm{~kg}$ & 0.30 & 0.35 & $0.40-0.55$ & & 0.30 & 0.40 & & \\
\hline $30-50 \mathrm{~kg}$ & 0.40 & 0.50 & $0.55-0.82$ & & 0.50 & 0.60 & & \\
\hline $50-85 \mathrm{~kg}$ & 0.55 & 0.65 & $0.82-1.02$ & & 0.65 & 0.80 & & \\
\hline $85-110 \mathrm{~kg}$ & 0.65 & 0.80 & $1.02-1.75$ & & 0.80 & 1.00 & & \\
\hline$>110 \mathrm{~kg}$ & 1.00 & 1.00 & & & 1.00 & 1.30 & & \\
\hline Non-suckling sows & 2.25 & EU & EU & EU & $\mathrm{EU}$ & & EU & $\mathrm{EU}$ \\
\hline \multicolumn{9}{|c|}{ Group housing in all farms ${ }^{b}$ required by when? } \\
\hline Non-suckling sows & 2013 & Present & Present & EU & $\mathrm{EU}$ & & Present & $\mathrm{EU}$ \\
\hline \multicolumn{9}{|c|}{ Is solid flooring required? } \\
\hline Fattening pigs & $\begin{array}{l}100 \% \text { slatted floors } \\
\text { allowed }\end{array}$ & $\begin{array}{l}\text { Lying area } \\
\text { is solid floor }\end{array}$ & $\begin{array}{l}65-75 \% \text { solid } \\
\text { floors }\end{array}$ & $\mathrm{EU}$ & \multicolumn{2}{|c|}{$40 \%$ solid floors } & $\mathrm{EU}$ & $\mathrm{EU}$ \\
\hline \multicolumn{9}{|l|}{ Light intensity } \\
\hline & $40 \mathrm{~lx}, 8 \mathrm{~h} /$ day & $75 \mathrm{~lx}, 8 \mathrm{~h} /$ day & $\begin{array}{l}75-1001 x \\
8 \text { h/day }\end{array}$ & EU & $\mathrm{EU}$ & & $\begin{array}{l}\text { EU + appropriate period of } \\
\text { rest from artificial lighting }\end{array}$ & EU \\
\hline \multicolumn{9}{|c|}{ Straw bedding (or likewise) required? } \\
\hline Fattening pigs & No & Yes & Yes & EU & EU & & EU & $\mathrm{EU}$ \\
\hline \multicolumn{9}{|l|}{ Minimum weaning age } \\
\hline Piglets & $\begin{array}{l}28 \text { days, with } \\
\text { specialised housing } \\
21 \text { days allowed }\end{array}$ & 28 days & 28 days & $\mathrm{EU}$ & $\mathrm{EU}$ & & EU & $\mathrm{EU}$ \\
\hline
\end{tabular}

Is un-anaesthetised castration allowed $^{\mathrm{c}}$ ? 
days: only under anaesthetic

and additional prolonged

analgesia by veterinarian)

Is tail-docking allowed?

Piglets

Docking of a part of the

tail is allowed $(<7$ days

of age, not routinely)

Is teeth clipping allowed?

Piglets

Uniform reduction of
corner teeth by grindin

or clipping is allowed

( $<7$ days of age, not

routinely)
No

No

EU

EU

No No EU EU

Not allowed unless other measures

to improve environmental

conditions or managemen

systems have been taken

in order to prevent tail

biting and other vices

Not allowed unless other measures

to improve environmental

conditions or managemen

systems have been taken in order

to prevent tail biting and

other vices

${ }^{\text {a }}$ In the Netherlands for stables built before 1 November 1998 and that have not been rebuilt or altered since 1 November 1998 the minimum space requirements for old stables apply. Stables or floors that have been built or rebuilt after 1 November 1998 have to comply with the minimum space requirements for new stables.

${ }^{\mathrm{b}}$ When buildings are built or rebuilt farmers have to adjust to group housing systems.

${ }^{c}$ In the UK castration is allowed by law, but all schemes in the UK except the organic schemes prohibit castration of male piglets. 


\section{The role of the Brambell report}

The Brambell committee started their farm visits and discussions in the summer of 1964. The findings described in the 1965 report were not surprising to some people but were an 'exposé' for others less familiar with, for example, intensive pig or poultry farming. The forward thinking and perceptive way in which the findings were reported had a significant role in shaping how farm animals were considered in the UK, and how they are treated and are protected by the law in the $\mathrm{UK}$, and in the EU. In this section, we examine the extent that the recommendations of the report have been met through regulations.

\subsection{Need for increased legislation}

Brambell suggested that more regulation was likely to be required to protect farm animals. In 1964, the legislation which could protect farm animals in the UK was limited. Since that time, farm animal legislation has expanded significantly, both at EU and at a national level as described in Section 2 of this paper. Almost all of the legislation described is based on measurable resources, space allowances, stocking densities, transportation times, finite measures of the availability of a commodity or resource for the animal, or a defined limit to the duration and severity of a process, many of which were mentioned in the Brambell report.

\subsection{Intensification and stocking density}

The Brambell report succinctly identifies the trend for increasing intensification that was occurring in the UK at the time of the report. This remains true of farming today: severe pressure on the price of products, on land, and the difficulties in obtaining planning consent for construction of intensive agricultural buildings in some countries, continue to make the 'cost per animal housed' a significant force for continued use of intensive stocking methods. The mechanism in EU legislation which has been used to prevent the introduction of the (technically achievable) high stocking rates, has been to set minimum space allowances per animal. Subsequent generations of legislation have tended to increase the space allowance per animal. The space allowance for pigs has seen alteration through regulation and Table 3 provides the current position for space allowances for pigs in seven European countries. Laying hen protection legislation provides a good example of this trend. The Brambell report recommended; (paragraph 67) The dimensions of the cage should be sufficient to enable the bird to stand upright at the point where the roof is lowest and to stretch a wing comfortably. We recommend that the three bird cage should measure not less than $20 \mathrm{in}$. wide and $17 \mathrm{in}$. deep and have an average height of $18 \mathrm{in}$. with the lowest part not less than 16 in.

The Brambell recommendation would equate to $650 \mathrm{~cm}^{2}$ per bird. Until 2003 it was permitted to stock laying hens at $450 \mathrm{~cm}^{2}$ per hen (e.g. the Welfare of Farmed Animals (England) Regulations 2000). After 2003, for hens in un-enriched cages, the space allowance increased to $550 \mathrm{~cm}^{2}$ per hen. EU Directive 1999/74/EC outlined the planned progression toward enriched cages by 2007 which provides for at least $750 \mathrm{~cm}^{2}$ cage area per hen, $600 \mathrm{~cm}^{2}$ of which should be useable, a minimum total cage size of $2000 \mathrm{~cm}^{2}$, a nest, litter so that scratching and pecking are possible, drinkers appropriate to the size of the group of birds and a perch, allowing at least $15 \mathrm{~cm}$ per hen. Thus, while the Brambell report recommended $650 \mathrm{~cm}^{2}$ in 1965; only in 2007 (if 
enriched cages are fully adopted by then) will hens achieve close to this, with $600 \mathrm{~cm}^{2}$ useable area.

For meat type birds (broilers), space allowance was also identified by the Brambell report as a concern. For practical reasons, the space available per bird (or the number of birds per unit space) is not widely adopted as a measure in broilers, but rather the mass of animals per unit space $\left(\mathrm{kg} / \mathrm{m}^{2}\right)$. This is because, as broiler birds grow, it is their size (mass) that becomes critical, not their number. Space allowance recommendations for broilers operate in the range $34-38 \mathrm{~kg} / \mathrm{m}^{2}$, and if, for example, an average broiler bird weighs $2.4 \mathrm{~kg}$, then this equates to approximately 16 birds per $\mathrm{m}^{2}$. The Brambell recommendation was $900 \mathrm{~cm}^{2}$ (i.e. $1 \mathrm{ft}^{2}$ ) per bird, which provided $1 \mathrm{~m}^{2}$ for 11 birds. Despite 40 years of changes in industry practice and legislation, the level recommended by Brambell has not been realised. Broiler producers indicate that increases in technology and improved management allow birds to be kept at higher stocking rates than were possible in 1965, and that economics demand high stocking levels. These claims may be true; the draft broiler directive is the first piece of EU legislation which provides the opportunity for producers to demonstrate, through measurable animalbased thresholds, that broilers can be farmed without incurring welfare impacts (foot pad burn and mortality in this case) and if so, they can be stocked at the higher permitted stocking level.

In many EU countries, an increasing proportion of livestock are farmed under reduced stocking density for example, in free range, extensive and organic farming systems as described in Section 3 of this paper. Despite the increase in land area required per animal, some of these systems are showing increased rather than decreased profitability through the increased price that can be asked of consumers for these animal products.

\subsection{Slaughter}

As well as discussing broiler space allowance, Brambell used broiler chickens as an example of an industry where the lack of protection at the time of slaughter raised possible concerns. Legislation to protect farm animals at the time of slaughter and killing is now adopted across the EU. Individual certification schemes may also specify standards in this area, for example, the killing of casualty animals.

\subsection{Animal health}

The Brambell report discussed the commonly stated view that only healthy animals kept to high welfare standards will be good 'producers'. (Paragraph 30) Many witnesses have represented to us that the growth rate of an animal for meat or the egg production of a laying hen are the only reliable objective measures of their welfare [...]. This is an over-simplified and incomplete view and we reject it.

Production parameters (weight gain, eggs per hen, milk yield) are data that farmers use on a daily basis, but do not form the basis of any EU or national welfare legislation. This likely reflects the view that an animal may grow and produce, but still live in conditions which cannot be considered to offer a good quality of life. Where thresholds have been set in the legislation, they almost exclusively relate to aspects of the animals' environment, such as space available, bedding, and feeding, and not on the animals' economic performance. Only the forthcoming draft broiler directive plans to use 'animal-based' measures (foot pad health and mortality) as thresholds within the legislation. 


\subsection{Stockmanship}

The Brambell report identified that stockmen in 1965 were coming under increasing time pressure, and were caring for more animals as systems increased in intensity. (paragraph 83) It is now quite common for a single stockman to be responsible for as many as 10,000 or more birds. . . This trend is not in itself objectionable but we think that it is important that certain inherent dangers should be recognised. We believe that all stock should be inspected at least once a day, and preferably twice. The concept of minimum inspection requirements, or of a tolerable interval between inspections for animals has been transposed into EU and national legislation (e.g. EU Directive 98/58/EC). It is of course possible to prescribe inspection intervals, but it is also clear that good stockmanship is not only a matter of the frequency with which animals are observed, but the 'quality' of the human intervention, for example during calving or farrowing, if adjustments in environmental temperature or ventilation are needed, or if animals are sick or become injured.

\subsection{Animal sentience}

The Brambell report also discussed the use of 'anthropomorphic' analogies between animal and human experience. However, the Brambell report makes it clear that stockmanship, stockperson training, empathy and experience are of very great importance in good animal care. The Brambell report recognised the value of a farmer who understands, empathises with, and 'cares' for the animals he or she farms, and Brambell's statement (paragraph 26) Animals show unmistakeable signs of suffering from pain, exhaustion, fright, frustration and so forth and the better we are acquainted with them, the more readily we can detect these signs still rings true if considered in this way. EU and national legislation, and the requirements of farm assurance standards reflect the importance placed on stockman care and experience.

\subsection{Licensing of farms}

The Brambell committee considered the possibility of licensing farms, but rejected this idea as cumbersome and unnecessary. This remains the case: farms are not formally licensed, however, most EU countries do require registration of farms with the competent authority for administrative and disease control purposes. The Brambell committee's statements on good stockmanship and the possible need for licensing could be considered premonitions of the concepts recently integrated into the European Rural Policy (2007-2013) (European Commission, 2004) which announced that direct payments to farmers within the EU could depend on farmers following 'good farming practises'

\subsection{Effect of chronic housing}

The Brambell report discusses the issues of severity and duration of conditions which may affect animal welfare and identifies that low level chronic conditions may have significant impacts on welfare through their long action. There are many possible examples of low level chronic conditions such as poorly maintained mesh or slat flooring, high environmental ammonia levels and bullying by pen mates. A specific example would be chronically wet bedding for calves. This may appear to be a temporary state of affairs and a 'snap shot' inspection of farms by state officials or by inspection bodies for farm assurance may not detect low level chronic 
conditions, or will mistake them for low level 'tolerable' issues as described by the Brambell committee. In this example, for the animals involved, an inability to rest in a dry area may represent a very significant chronic challenge to comfort.

\subsection{Mutilations}

The Brambell report identifies tail biting as a concern in pig production and discusses the implications of mutilations such as tail docking in pigs and also beak trimming in poultry. EU legislation permits individual countries to make recommendations on the use of these procedures (e.g. EU Directive 91/630/EEC: "Neither tail docking nor tooth clipping shall be carried out routinely but only where there is evidence, on the farm, that injuries to sows' teats or to other pigs' ears or tails have occurred as a result of not carrying out these procedures."').

Tail docking of pigs continues to be common across Europe, however in Sweden and Norway, tail docking and teeth clipping is prohibited. Research carried out over the years since Brambell has shown that environments which allow pigs to root in soil or bedding, and to escape aggressive attention from others greatly reduces the incidence of tail biting.

\subsection{The necessity of a scientific advisory body}

The Brambell report recognised that his 'one off' report needed to recommend the establishment of a more formal system for reviewing farm animal welfare to have an ongoing effect and recommended that provision should be made in the Act for the establishment of a Farm Animal Welfare Advisory Committee to advise the minister on all these matters. The Farm Animal Welfare Advisory Council, which became the Farm Animal Welfare Council in the UK (FAWC) and equivalent organisations in many European and non-European countries, stems from this initial concept. It is a semi-independent body which could advice government and legislators on issues relating to farm animal welfare. In the UK, the periodic FAWC reports have been seen as valuable indicators of issues in farm animal welfare and pointers for areas where protection measures should be directed.

\section{What comes next?}

Many certification bodies now make the principles of space, food, water, freedom from disease and freedom to express a range of behaviours the basis of the assessment which they may carry out. The five freedoms stem almost directly from the initial issues identified by the Brambell report. The 'on-farm' assessment of these areas has been based on practical realities, such as the ability to measure an animal house or the availability of a heating or ventilation system, in contrast to the apparent difficulties in assessing whether the space available is used effectively by the animals, is clean (some animals choose to use space for bed areas and some for defecation), or whether animals are able to escape bullying or tail biting. There are moves in some certification schemes to try and start to include animal-based measures, for example, the incidence of lameness in cattle or sheep, of foot pad lesions in poultry, or the comfort behaviours of animals in cubicles and stalls and the response of animals to their keepers in the inspection process. The Welfare Quality ${ }^{\circledR}$ project (www.welfarequality.net) aims to help this progression from purely resource-based assessment to the inclusion of measures which indicate the direct effects on animals. 
Animal legislation, the assessment of animal welfare, and the implementation of the law and practical strategies from, for example farm assurance schemes, will progress as farming develops and world trade in animal products becomes more complex. The Brambell report was remarkably prescient of issues and problems, many of which still exist today.

\section{Conclusion}

In summary, the Brambell report gathered together a number of concerns about UK farm animal welfare issues, in a clear, firm and authoritative way. The Brambell committee's findings either predicted, or initiated many areas where regulation now occurs but, the recommended levels of, for example, space allowance, or reduction in mutilations which he made, have often not been fully achieved. Some of the committee's statements still feel very relevant, but others are no longer relevant as farming systems have changed or legislation has appeared (for example in stunning and slaughter). The Brambell committee proposed areas where legislation was lacking and much of the suggested legislation now exists, and recommended that a body independent of the government should be set up to advise on farm animal welfare issues in the long term and this is the case in many European countries now.

\section{Acknowledgements}

The present study is part of the Welfare Quality ${ }^{\circledR}$ research project which has been co-financed by the European Commission, within the sixth Framework Programme, contract no. FOOD-CT2004-506,508. The text represents the authors' views and does not necessarily represent a position of the Commission who will not be liable for the use made of such information.

\section{References}

Anonyme, 1997.Treaty of Amsterdam amending the treaty on European Union, the treaties establishing the European communities and related acts, Official Journal, 340, available at http://eur-lex.europa.eu/en/treaties/dat/11997D/htm/ 11997D.html (last visit October 2, 2007).

Bock, B., Van Huik, M., 2007. Pig farmers and animal welfare: a study of beliefs, attitudes and behaviour of pig producers across Europe. In: Kjaernes, U., Miele, M., Roex, J. (Eds.), Attitudes of Consumers, Retailers and Producers to Farm Animal Welfare. WelfareQuality ${ }^{\circledR}$ Report No. 2. Cardiff University, Cardiff, pp. 73-124.

Bock, B., van Leeuwen, F., 2005. Review of socio-political and market developments of animal welfare schemes. In: Roex, J., Miele, M. (Ed.), Farm Animal Welfare Concerns, Consumers, Retailers and Producers. WelfareQuality ${ }^{\circledR}$ Report No. 1. Cardiff University, Cardiff, pp. 115-167.

Brambell, R., 1965. Report of the technical committee to enquire into the welfare of animals kept under intensive livestock husbandry systems. Her Majesty's Stationery Office. London, 85 pp.

Early, R., 1995. A Guide to Quality Management Systems for the Food Industry. Blackie Academic and Professional, London, 308 pp.

European Commission, 2004. Fact Sheet: New Perspectives for EU Rural Development. Office for Official Publications of the European Communities, Luxembourg, 16 pp.

Farm Animal Welfare Council, 1992. FAWC updates the five freedoms. Vet. Rec. 17, 357.

Manning, L., Baines, R.N., Chadd, S.A., 2006. Quality assurance models in the food supply chain. BFJ 108, 91-104.

Murdoch, J., 2005. A comparative analysis of retail structures. In: Roex, J., Miele, M. (Ed.), Farm Animal Welfare Concerns, Consumers, Retailers and Producers. WelfareQuality ${ }^{\circledR}$ Report No. 1. Cardiff University, Cardiff, pp. 81112.

Roe, E., Marsden, T., 2007. Analysis of the retail survey of products that carry welfare-claims and of non-retailer-led assurance schemes whose logos accompany welfare-claims. In: Kjaernes, U., Miele, M., Roex, J. (Eds.), Attitudes of 
Consumers, Retailers and Producers to Farm Animal Welfare. WelfareQuality ${ }^{\circledR}$ Report No. 2. Cardiff University, Cardiff, pp. 33-69.

Roe, E., Murdoch, J., Marsden, T., 2005. The retail of welfare-friendly products: a comparative assessment of the nature of the market for welfare-friendly products in six European countries. In: Butterworth, A. (Ed.), Science and Society Improving Animal Welfare, WelfareQuality ${ }^{\circledR}$ Conference Proceedings, Brussel, NP, November 17-18. 